\title{
Um papel histórico para a teleficção: a minissérie Anos rebeldes e a cultura histórica brasileira dos anos 1980
}

\author{
A historical role for TV fiction: the miniseries Anos rebeldes and the \\ Brazilian historical culture of the 1980 s
}

\author{
Roberto Abdala Junior* \\ abdalajr@gmail.com \\ Professor \\ Universidade Federal de Goiás \\ Rua 56, 635, apart. 1701 - Qd. B19; Lt. 17/18 - Jardim Goiás \\ 74.810-240 - Goiânia - Goiás \\ Brasil
}

\begin{abstract}
Resumo
O artigo coloca em debate o emprego da teledramaturgia como elemento da cultura brasileira revelador de aspectos "silenciados" das memórias sociais e merecedor de se tornar fonte nas pesquisas históricas. O objeto da pesquisa consiste da análise da minissérie Anos rebeldes para investigar de que maneira repercutiu nas manifestações pró-impeachment do Presidente Fernando Collor de Mello. O argumento é que, ao assistir a Anos rebeldes, o público jovem encontrou uma narrativa na qual, por um lado, eram articuladas algumas das experiências de décadas anteriores e, por outro, orientaram suas ações na esfera pública. A análise referenciou-se nos argumentos de Rüsen e da Didática da História, bem como na articulação de três autores, cujas teses permitem abordar uma narrativa audiovisual como uma minissérie: Vygotsky, Bakhtin e Williams. A investigação exigiu que, metodologicamente, noções de outros campos fossem empregadas. A pesquisa também sugere uma nova categoria analítica: as "memórias coletivamente compartilhadas".
\end{abstract}

\section{Palavras-chave}

História; Memórias; Didática da história.

\begin{abstract}
The article debates the use of television drama as part of Brazilian culture, revealing aspects "silenced" social memories and therefore worthy of becoming a source in historical research. The object of the research is a year in Brazilian history (1992) when there was a display of the miniseries occurred Anos rebeldes and pro-impeachment protests of President Fernando Collor de Mello, in which students were references to that work of TV fiction. Our argument is that when watching the work, the public found a narrative of historical culture in which, on the one hand were articulated their experiences from the period of military dictatorship and, on the other, guided his action in the public sphere. The analysis referenced on the arguments of Rüsen as epistemological foundation. Research demanded that, methodologically, other fields notions were employed, as suggested Rüsen to Teaching studies of history. In this sense, we turn to authors who conceive their objects in anthropological bias, recognizing the language as an essential tool of sociocultural interaction processes, although their fields of research were different: Vygotsky, focusing on mind; Bakhtin, language and Williams in the media. The research also suggests a new analytical category: the "collectively shared memories."
\end{abstract}

Keywords

History; Memoirs; History didactics.

Recebido em: 27/8/2015

Aprovado em: 1/6/2016

* O presente trabalho apresenta parte dos resultados do doutorado (UFMG/2009), cujo processo de pesquisa foi financiado, durante dois anos, pelas agências de pesquisa CAPES e depois CNPq. 
As reflexões que apresentamos surgiram ao longo da pesquisa de doutorado: um estudo sobre as chamadas memórias sociais, ${ }^{1}$ relativas à ditadura militar brasileira nos anos 1980. A investigação nasceu a partir de dois "acontecimentos" ocorridos em 1992: a exibição de uma minissérie pela Rede Globo de Televisão chamada Anos rebeldes, cujo contexto histórico da trama coincide com o período de vigência da ditadura e o processo de impeachment do ex-presidente Fernando Collor de Mello, marcado por grandes manifestações públicas, nas quais a presença de estudantes era maciça. O mais intrigante foi que os dois acontecimentos apresentaram uma incontestável e rara relação: os estudantes que assumiram um protagonismo político do qual haviam se afastado desde o início dos anos 1970, referiam-se deliberadamente à minissérie, não somente nas palavras de ordem, mas numa diversidade de signos que animavam as ações públicas das quais participavam.

Ao investigar aqueles acontecimentos, nos deparamos com as lutas pelas memórias da ditadura, além de outra categoria de memória que, a rigor, não era contemplada entre aquelas postuladas como "nacionais", nem por militantes de esquerda, nem por militares. A imersão nos anos 1980 nos levou a analisar alguns sinais ${ }^{2}$ da cultura histórica ${ }^{3}$ de época e a explorar a possibilidade de a teleficção, no afã de dialogar - no sentido bakhtiniano - com o repertório de "todas" as memórias do grande público, ${ }^{4}$ ter acolhido também uma categoria de memória que não costuma figurar entre memórias consideradas nacionais pelos agentes sociais que, tradicionalmente, disputavam poder na esfera pública: as "memórias coletivamente compartilhadas".

No final da pesquisa a hipótese que orientava todo o trabalho sofreu uma mudança significativa, pois passamos a considerar que Anos rebeldes, ao trazer as mobilizações dos anos 1960 para a televisão do início dos anos 1990, "dialogava" não somente com as memórias daqueles anos "revolucionários" e não rebeldes, como propõe o título da obra -, mas também com memórias de experiências mais recentes dos brasileiros comuns: dos então emergentes movimentos sociais da década que se encerrava. A hipótese que doravante passamos a alimentar, embora fosse difícil de investigar, seria facilmente

\footnotetext{
${ }_{1}^{1}$ A partir de uma análise dos estudos de Candau (2012), Ricoeur (2004), Jelin (2002), Yerushaumi (1989) Halbwachs (1990) Fentress \& Wickham (1994) consideramos que seria mais adequado nos estudos sobre memória lidar com a noção de cultura histórica proposta por Rüsen (2001, 2007a, 2007b; 2009, 2014). Neste trabalho empregaremos o termo memória social como contraponto de memória individual (FENTRESS; WICKHAM 1994) e memória coletiva como memória de grupos (HALBWACHS 1990) que, por ora, será suficiente para dar andamento às nossas reflexões.

2 Segundo Carlo Ginzburg há um paradigma analítico - antropológico e preso à interpretação das imagens que recorre a alguns elementos (sinais) que não seriam reconhecidos numa análise ligeira, mas somente por um estudo atento aos detalhes. Trata-se de um método análogo aos procedimentos da medicina ("semiótica médica"). Os sintomas apresentados pelos homens (medicina) e/ou por expressões de uma cultura (história) são, pois, considerados sinais pelos quais se elucida a causa, seja doença ou aspectos antropológicos de uma sociedade (GINZBURG 1989).

${ }^{3}$ A noção de "cultura histórica" é empregada segundo a argumentação de Rüsen e contempla as chamadas memórias coletivas e/ou sociais, mas também a historiografia, a cultura histórica escolar e política, além de toda a diversidade da produção cultural de uma sociedade que, de alguma maneira, tem por foco o passado, a história (RÜSEN, 2001; 2007a; 2007b; 2009; 2014). Merece atenção o argumento de Jelin, segundo o qual a memória também "se manifesta nas ações e expressões, [de forma que] antes de re-presentar o passado, incorporam-no performativamente" (JELIN 2002, p. 37, tradução livre).

${ }^{4}$ A noção de "grande público" que exploramos neste trabalho é inspirada nos argumentos da obra Elogio do grande público: uma teoria crítica da televisão (WOLTON 1996).
} 
defensável com argumentos e reflexões de Raymond Williams, Mikhail Bakhtin no que se refere à arte e à cultura, e aos postulados de Jörn Rüsen, sobre a epistemologia da ciência História.

Sob o ponto de vista empírico era possível comprovar a hipótese, em larga medida, por meio das experiências ocorridas com o cinema ao longo do século $X X .{ }^{5}$ Afinal, a sétima arte, então com quase um século de existência, nunca mediu esforços para cumprir o papel que na época foi atribuído à minissérie: mais do que participar, interferir em processos históricos concretos. ${ }^{6}$ Testemunhos de época atestam a relação intrínseca e evidente entre os dois eventos e indicam que houve em 1992 um raro momento na sociedade brasileira em que memórias, história e teleficção estabeleceram relações de tal ordem que poderiam se configurar em objeto de estudo para o campo da História. ${ }^{7}$

Noutros termos, a história recente do Brasil apresentava uma oportunidade ímpar para que se realizasse um estudo no qual evidências empíricas não deixavam dúvidas quanto ao impacto de uma obra de teledramaturgia sobre a sociedade, cuja repercussão mais evidente se deu entre os estudantes. Mas, um estudo desta natureza exigia uma abordagem que levasse em conta, sobretudo, as circunstâncias históricas que fizeram a recepção da obra, inusitadamente, favorável à ação social. Somente assim, a imbricação daqueles dois acontecimentos (cultural e político) poderia ser estudada.

A análise demandava uma abordagem que permitisse pensar obras audiovisuais, memórias - individuais e sociais - e História de maneira articulada. 0 estudo que apresentamos a seguir visa, pois, estudar uma obra de teleficção que, por uma série de circunstâncias históricas, configurou-se como um dos elementos centrais daquele momento: a minissérie Anos rebeldes. Não se trata, sem dúvida, de uma estrita análise de obra teleficcional, mas sim de uma investigação que busca compreender o papel que uma obra de teleficção desempenhou na sociedade brasileira no ano de 1992. Um campo de pesquisa recuperado, contemporaneamente, para a História por Rüsen: a Didática da História (RÜSEN 2014; 2015).

O objetivo deste trabalho é, pois, apresentar parte dos resultados da pesquisa, sobretudo algumas conclusões, de maneira a demonstrar como a teleficção pode ser tomada como fonte histórica, considerando-a obra de arte ordinária característica do Brasil contemporâneo e empregando como evidências históricas aqueles dois acontecimentos. Nesse sentido, bastava

\footnotetext{
${ }_{5}^{5}$ Uma delas, especialmente rica, por referir-se à época da própria ditadura quando o filme Terra em transe (1967) de Glauber Rocha foi exibido na cidade do Rio de Janeiro e assistido pelo músico Caetano Veloso.

${ }^{6} \mathrm{~A}$ ideia de um cinema que pretende desempenhar uma ação militante pode ser atribuída, desde o cinema norte-americano do início do século XX, aos cineastas soviéticos dos anos 1920 (Einsentein, Vertov, etc.), passando pelo cinema europeu do pós-guerra, ao Cinema Novo brasileiro dos anos 1960. Sobre a possibilidade de o fenômeno ter um significado mais amplo do que vem sendo considerado na "cuktura histórica" nacional, podemos nos remeter a, pelo menos, dois trabalhos: Anderson (2005) que defende o papel da imprensa no século XIX na formação das "Comunidades imaginadas" e Kornis (2000) que analisa uma função análoga pretendida pela Rede Globo, desde os anos 1980, projeto que seria realizado por meio das minisséries.

7 A revista de maior circulação nacional - a Veja, destacava que, nos cinquenta mil panfletos e vinte mil cartazes distribuídos pela União Brasileira de Estudantes Secundaristas que visavam incitar a participação dos jovens na manifestação de São Paulo "se lia 'Anos rebeldes, próximo capítulo: Fora Collor, Impeachment Já'". Um pouco mais tarde, a revista IstoÉ, então a maior concorrente de Veja, afirmava, categoricamente: "A panfletagem eletrônica, patrocinada involuntariamente pela Rede Globo de Televisão com a minissérie Anos rebeldes ajudou a engrossar as manifestações".
} 
encontrar em Anos rebeldes "diálogos" propostos e/ou travados com outras obras-história e/ou obras-memória que compunham o repertório da cultura histórica brasileira sobre os anos 1960 naquele momento. No entanto, no decorrer de nossa investigação deparamo-nos com outra categoria de memórias que denominamos "coletivamente compartilhadas", cuja definição será esclarecida a seguir.

\section{História e teleficção: em busca de um quadro analítico}

Um quadro teórico vinha mostrando sua eficácia em análises cujo espectro se estendia da Psicologia Sociocultural à Antropologia, da Comunicação à Sociologia da Cultura, especialmente com relação aos meios de comunicação. Algumas dessas ideias foram disseminadas no Ocidente a partir dos anos 1970, quando as teses de Vygotsky, Bakhtin e seu círculo, finalmente, passaram a ser conhecidas fora da União Soviética. Articuladas às proposições de Raymond Williams formavam um quadro teórico que permitia estudar o papel estruturante desempenhado pela linguagem/arte/mídia na era da reprodutividade técnica, embora contrariassem algumas correntes analíticas recentes, pois exigiam um estudo da obra contextualizada cultural e historicamente.

Neste quadro analítico, não era possível considerar obras audiovisuais como fundadoras de memórias, ${ }^{8}$ mas sim considerá-la como "arte" - ordinária (WILLIAMS 2003) - que oferece articulação às experiências sociais de maneira inusitada, logrando acolhida positiva entre amplos segmentos da população brasileira, devido à trajetória histórica que a teleficção havia cumprido na cultura brasileira, colocando temas importantes do presente como aspecto explorado pela trama (HAMBURGER 2005). Uma obra como Anos rebeldes poderia ser concebida como narrativa, cujo caráter antropológico recuperado no presente como propõe Rüsen - apreendeu, organizou, descreveu e comunicou (WILLIAMS 2003) experiências sociais, fazendo com que lembranças individuais fossem articuladas em discursos partilhados coletivamente.

Segundo esse enquadramento teórico, a obra não teria a possibilidade de mobilizar multidões per si. O papel cumprido pela minissérie Anos rebeldes consiste em formular diálogos com a "cultura histórica" (RÜSEN 2009) de época sobre a ditadura, nas interações (WILLIAMS 1979) que estabelece com o público ao ser exibida. A partir dos diálogos engendrados com as obras-memórias, as obras de História e outras formas de expressão cultural voltadas para representar o passado, formando a "cultura histórica", é que ela ganha significados, ainda que muitas vezes reconfigurados por meio da narrativa. Nesse sentido, a obra somente pode encontrar a repercussão ocorrida em 1992 porque havia uma situação histórica na qual o repertório que compunha a cultura histórica do público assegurava a ela uma resposta daquela natureza. Noutro contexto, isso não aconteceria; pelo menos, não da maneira como ocorreu naquele ano. 
Alguns dos elementos que contribuíram para a construção daquele "acontecimento-problema" precisavam ser tomados, necessariamente, sob o viés pelo qual as obras dos autores que nos servem como referências autorizam: conceber a criação coletiva da minissérie, cuja linguagem era acessível ao grande público; considerar sua exibição em interação com um contexto histórico no qual seus significados sociais e políticos consolidam-se, repercutem e podem até ser ampliados e, por fim, contar com a existência de um repertório cultural partilhado - discursivo - e experiencial (uma cultura histórica), ${ }^{9}$ com o qual a obra pudesse estabelecer "diálogos".

Nosso argumento é que esse conjunto de fatores articulados da maneira como ocorreu em 1992 permitiu que os "diálogos" travados entre a minissérie e as demais obras que compunham a cultura histórica fundamentassem os significados nas experiências coletivas compartilhadas por amplos segmentos da população brasileira naquele momento. Anos rebeldes ofereceu, pois, uma narrativa cuja descrição correspondia (ainda que parcialmente) às experiências, então recentes, que a sociedade brasileira partilhava de tal forma que se forjou uma "resposta" social, não somente àquela obra, mas a toda a história que ganhava expressão e significado por meio dela.

Dito de outra maneira, todos estes elementos, reunidos pelas circunstâncias históricas, levaram alguns segmentos da população a orientar sua ação (RÜSEN 2001 ; 2014) conforme aquela narrativa. Uma obra que, embora não pudesse ser caracterizada como científica era concebida, genericamente, como uma narrativa histórica - uma interpretação verossímil do passado (RÜSEN 2001, 2007a; 2007b) - à disposição do grande público e, nesses termos, experiências ordinárias de amplos segmentos da população foram apreendidas, organizadas, descritas e comunicadas/compartilhadas por meio da minissérie.

\section{Uma estratégia de abordagem: "enunciado" e os discursos em "diálogos"}

As considerações de Williams definem algumas diretrizes orientadoras para uma investigação que envolva uma obra de ficção televisiva. Metodologicamente, entretanto, seus argumentos e reflexões não enfocam as estratégias (especialmente de linguagem) que obras desta natureza empregam. Uma lacuna que buscamos preencher com as teses de Mikhail Bakhtin. ${ }^{10}$

O filósofo da linguagem, contrapondo-se à tradição linguística de considerar o texto divorciado do contexto, enfocou em suas reflexões e investigações a ação completa de "enunciação" da qual o discurso participa - considerando os contextos sociocultural, discursivo, verbal e não-verbal. ${ }^{11}$ Nas suas análises, demonstra que todos os discursos se caracterizam por serem dialógicos. O conceito de "dialogismo" constitui um elemento central nas suas proposições,

\footnotetext{
${ }^{9}$ Diversos autores têm feito uso da ideia, entre eles, Rüsen (2007; 2014), Abreu, Soihet e Gontijo (2007).

${ }_{10}$ A respeito de articulações entre premissas e proposições de Vygotsky, Bakhtin e Williams, consultar este último (WILLIAMS 1979, p. 27-59).

${ }^{11}$ Segundo Bakhtin, o tema que consiste do significado sociocultural e historicamente situado, não do discurso, mas "da enunciação é determinado não só pelas formas linguísticas que entram na composição (as palavras, as formas morfológicas ou sintáticas, os sons, as entonações), mas igualmente pelos elementos não verbais da situação" (BAKHTIN 1997, p. 128, grifo nosso.).
} 
porque é ele que desloca o foco da análise dos discursos para o enunciado - a "unidade da comunicação discursiva" (BAKHTIN 1992, p. 270), além de manter em tensão dinâmica os processos interativos ocorridos nas práticas socioculturais, cujos resultados configuram significados.

Bakhtin defende que os discursos, ao serem enunciados, realizam "diálogos" em dois contextos culturais diferentes. O que nos interessa é o que ele considera mais complexo e amplo, o da "comunicação cultural" - dos discursos científicos, artísticos, políticos etc. (BAKHTIN 1992). Ao circular pela cultura, o discurso se depara com outros e "não pode deixar de participar com eles de uma interação viva e tensa". Nesse sentido, qualquer discurso "nasce no diálogo como sua réplica viva, forma-se na mútua-orientação dialógica no discurso de outrem" (BAKHTIN 1998, p. 88-89).

Tomando estas reflexões como referência, Bakhtin reconhece outra característica precípua dos discursos: a "reação responsiva". Segundo ele,
A obra, assim como a réplica do diálogo, visa à resposta do outro (dos outros), uma compreensão responsiva ativa, e para tanto adota todas as espécies de formas: busca exercer uma influência didática sobre o leitor, convencê-lo, suscitar sua apreciação crítica, influir sobre êmulos e continuadores, etc. A obra predetermina as posições responsivas do outro nas complexas condições da comunicação verbal de uma dada esfera cultural. A obra é um elo na cadeia da comunicação verbal; do mesmo modo que a réplica do diálogo, ela se relaciona com as outras obras-enunciados: com aquelas a que ela responde e com aquelas que Ihe respondem [...] (BAKHTIN 1992, p. 197, grifo nosso).

A "reação responsiva" constitui-se, pois, em noção operatória para análise de uma forma de expressão cultural como a minissérie, pois anima toda obra, interpela seu(s) interlocutor(es) e, como uma réplica do diálogo, busca seu engajamento, pretendendo engendrar uma compreensão responsiva por parte dele(s). Afinal, os discursos são forjados e enunciados visando a exercer uma influencia sobre seu(s) interlocutor(es), convencê-lo(s), suscitar nele(s) apreciações críticas.

No quadro teórico elaborado (e depois empregado) por Bakhtin, ${ }^{12}$ as "respostas" cognitivas relativas à "compreensão responsiva ativa" são tomadas como outros discursos, cuja principal característica é ainda o diálogo. ${ }^{13}$ Afinal, a obra sempre deve ser considerada como um elo na cadeia da comunicação verbal e/ou não verbal e, do mesmo modo que a réplica do diálogo, ela consiste de uma resposta contextualizada da(s) interpelação(ções) que lhe foi(ram) formulada(s).

Nessa medida, todo o processo de comunicação, no interior do qual ocorrem as enunciações e as reações responsivas, pode ser tomado como um contexto dialógico no qual os diálogos são, permanentemente, instituídos entre aqueles que compartilham o contexto da comunicação cultural. A noção de "diálogo" estende-se, pois, do sentido primário do discurso entre duas pessoas, a outros

\footnotetext{
12 Referimo-nos a sua obra: A cultura popular na idade média e no renascimento; o contexto de François Rabelais (BAKHTIN 1996).

13 Merece destaque o fato de trabalhos contemporâneos apresentarem resultados semelhantes, como pode ser confirmado nas obras de Wertsch (2002) e Carretero (2006).
} 
domínios, até mesmo metafóricos, como afirma Stam. O dialogismo, segundo o autor, pode referir-se inclusive "às maneiras como o discurso fílmico é conformado pelo público, cujas reações potenciais são levadas em conta" (STAM 1992, p. 34).

$\mathrm{Na}$ observação acima que corrobora o argumento de Bakhtin assenta-se a possibilidade de pensarmos a noção de "reação responsiva" como operatória na análise de uma obra audiovisual. Afinal, como esclarece Bakhtin, a "obra predetermina as posições responsivas do outro nas complexas condições da comunicação verbal de uma dada esfera cultural". Mas, a clara dimensão do significado que os conceitos de "dialogismo" e de "reação responsiva" representam como elementos operatórios na análise de uma minissérie, somente podem ser apreendidas com um exercício de aplicação empírica que não é possível ser realizada no espaço deste trabalho.

\section{Lembranças, memórias e narrativa audiovisual em interação}

A minissérie Anos Rebeldes, seguindo esse enquadramento teórico, procura dialogar com a cultura histórica sobre o período da ditadura civilmilitar que foi-se engendrando ao longo dos anos. Uma incursão nesta seara seria proveitosa, se não para esclarecer, pelo menos para comprovar sua eficácia e também para demonstrar o espectro de possibilidades que se abre a partir do quadro teórico-metodológico que construímos. O campo desses diálogos é muito difícil de dimensionar, pois é composto pelas mesmas formas de expressão cultural que compõem a "cultura histórica" sobre o tema na época da enunciação/exibição da obra.

O exíguo espaço para explorar esse universo amplo nos obriga a indicar, somente, um dos inúmeros aspectos nos quais é possível comprovar as proposições dialógicas com as quais a produção orientou seu trabalho, no momento da elaboração da narrativa: a verossimilhança. Importa atentar para o fato deste aspecto; além de interpelar a "cultura histórica" sobre a ditadura, também confere credibilidade à narrativa por parte do público, pois tem um caráter diégetico na trama e não se esgota nestas observações. A verossimilhança será analisada segundo dois elementos: cenários e os "painéis documentais" - uma novidade constituída por imagens e imagens-movimentos de época inserida na narrativa tradicional, criada pelo cineasta Silvio Tendler, responsável por realizá-los.

Na minissérie, "há uma espetacular reconstituição de época - não apenas de cenários, [...] mas também nos fatos culturais que marcaram o país" (GIANNINI 1992, p. 86). O esmero com a produção que marcava as obras da TV Globo desde os anos 1970 chegou a tal nível que a revista IstoÉ considerou que "Até os integrantes da chamada geração 68 vão achar um exagero" (IstoÉ 1992, p. 62). A narrativa recorre, pois, a uma estratégia clássica das produções audiovisuais: as reconstituições de cenários e figurinos de época.

Numa narrativa audiovisual temos o apelo à verossimilhança de cenários e figurinos, mas também a interpelação do repertório das experiências individuais de brasileiros que compunham o público da minissérie. Tanto aqueles para os quais era fácil lembrar e contextualizar o que vinha sendo representado, quanto 
para os mais jovens que poderiam deter aquelas memórias noutros registros, ou nem mesmo lembrar - em ambos os casos a minissérie teria um significado mais expressivo. ${ }^{14}$

O primeiro dos painéis documentais, iniciado com um recorte de jornal no qual vemos diversos generais, entre eles, Castelo Branco, lê-se a seguinte manchete: "Generais acusam governo de promover baderna". A seguir, vemos uma foto de "Che" Guevara, em "close"; tomadas do comício da Central do Brasil, ocorrido pouco antes do golpe, onde vemos Jango discursando. Logo a seguir há um recorte de jornal sobre as Reformas de Base e Jango conclamando apoio da população. Aparece um recorte de jornal sobre a "Marcha da família, com Deus, contra o comunismo". Depois, outro no qual se lê: "Marinheiros amotinados. Grave crise nas Forças Armadas". O painel é finalizado com a notícia de que as tropas marcham contra Jango.

Observa-se, não somente uma contextualização histórica bastante sofisticada, com imagens ordenadas em uma narrativa audiovisual, como uma interpelação das memórias históricas do público, relativas aos acontecimentos que antecederam o golpe militar de 1964. Afinal, o que confere significado racional às imagens é o repertório cultural de uma sociedade em uma determinada época (AUMONT 2001). Noutros termos, para aqueles que não detivessem algum conhecimento sobre as imagens e ao que se referiam seu significado ficaria muito empobrecido.

A música que serve de fundo musical às cenas que são apresentadas é a versão de Pra não dizer que não falei de flores, apresentada no festival da canção (1968) em um dos últimos painéis (Anos Rebeldes, 2003; disco 2; 2:09:03 - 2:09:03) do segundo disco. Nas imagens que são apresentadas por ele, as cenas de rua são mais violentas, aparecem cenas da insurreição dos estudantes no México, o incidente do PAR-SAR, no qual o capitão Sergio Carvalho, da Força Aérea Brasileira, denuncia o plano para assassinar líderes da oposição. Seguem-se cenas do congresso da UNE em Ibiúna, mostrando a prisão de estudantes e finda com a apresentação do AI-5. Num painel seguinte, o recorte de jornal estampa: "Governo nega a prática de tortura" (Anos Rebeldes, 2003; disco 3; 00:32:29).

A operação didática - como propõem, diferentemente, Rüsen e Bakhtin ${ }^{15}$ das sequências é possível reconhecer até mesmo nas transcrições escritas. No entanto, os significados são construídos nos diálogos propostos pela narrativa. São as imagens isoladas, as sequências narrativas e a narrativa completa que interpelam o público. Interpelam, na verdade, suas lembranças individuais, suas memórias individuais e coletivas, a cultura histórica que compõe o repertório compartilhado sobre a experiência da ditadura.

Assim, para que a narrativa, com sua versão ficcional do passado, fosse apreendida pelo público, conforme pretendiam os autores, era necessário que

${ }^{14}$ Sobre o impacto do cinema sobre sobreviventes dos campos de concentração, ver Pollak (1989)

15 Rüsen considera que uma das dimensões narrativas de caráter histórico consiste em apresentar as relações entre passado e presente, enquanto Bakhtin está mais preocupado em como cada discurso opera as características estéticas e retóricas que Ihes são próprias, como vimos acima. 
as imagens e os acontecimentos fizessem parte de seu repertório cultural, de sua cultura histórica. Merece atenção o fato de que não existe possibilidade de a obra ser apreendida igualmente por todos aquelas que compõem o "grande público". Há também, nesse caso, uma tensão histórica - como Rüsen sugere que ocorra para a narrativa da historiografia - que se estabelece, exatamente, porque existe uma proposta de diálogo com o que o passado legou aos brasileiros durante período ditatorial.

A resumida série de "painéis documentais" que apresentamos indica que, embora Anos rebeldes tenha omitido aspectos importantes do golpe e da ditadura, a narrativa não se negou a contemplar os mais importantes discursos sobre esse passado que compunham a cultura histórica sobre o tema na época da produção da obra. No entanto, se Anos rebeldes pudesse obedecer a uma categorização básica quanto às escolhas que orientaram a obra, para além da literatura que lhes deu inspiração, não é possível negar que sua opção foi pelos "revolucionários", a despeito do uso do termo não ser admitido nem mesmo no título.

\section{O passado no presente: memórias, cultura e televisão}

Ao visitarmos a história brasileira não é difícil perceber como as elites, sistematicamente, tentaram silenciar as formas de ação política e/ou social autogestadas da sociedade, particularmente no que se refere às iniciativas de segmentos populares (WELFORT 1973). Se não foi possível sufocar todas as suas manifestações, sobretudo no que tange à política, isso se deve ao caráter intrínseco das sociedades, sempre capazes de oferecer alguma forma de resistência, explícita e/ou velada.

No contexto brasileiro dos anos 1960 em diante, em função da opressão política perpetrada pelo Estado ditatorial, as lutas pela representação do passado nacional, bem como as múltiplas formas de atribuição de significado às experiências e memórias sociais ganham importância superlativa, expressando as mazelas deste embate. Nos anos que se seguiram à ditadura tais disputas se acirram, aprofundam e disseminam por toda a sociedade, pois as experiências que militares pretendiam negar eram exatamente as mesmas que seus opositores, em diversos níveis - não somente os militantes de esquerda, procuravam dar voz e, eventualmente, enfatizar (REIS FILHO 2004).

No espaço deste texto não cabe, entretanto, aprofundar todos os aspectos empíricos relacionados aos embates pela memória/História nacional, exercício que desenvolvemos noutro trabalho (ABDALA JUNIOR 2009). No entanto, vamos apresentar, a seguir, uma análise que lida com alguns desses aspectos no campo de nossas reflexões.

\section{A invenção da nação: um Brasil sem exclusão}

Inicialmente, seria importante recordar que o processo de invenção da "nação" brasileira, no bojo dos demais movimentos que visavam a esse mesmo propósito, foi engendrado pelas elites, senão sócio-econômicas, muitas vezes culturais ou militares. Nessa empreitada das elites brasileiras, é fácil observar a prática de ignorar ou negligenciar as manifestações de segmentos populares, 
tanto em momentos que estes agiam na esfera pública, quanto naqueles voltados para reivindicações relativas à ação do Estado (MOTA 1977).

Sabemos que a produção de memórias no Brasil - como tradicionalmente aconteceu nos países ocidentais - coube, sobretudo, a esses mesmos agentes sociais. ${ }^{16}$ Negligenciados, os segmentos populares brasileiros escarneciam dos grupos que se arrogavam da liderança social, pelo menos desde o final do século XIX, conforme título da obra de Carvalho expressa muito bem. Em Os bestializados (CARVALHO 1987) nos deparamos com segmentos populares que, não somente tinham claro o que Ihes impingia a elite política, como percebemos que a ideia de "bestializado" se aplicava, melhor e ironicamente, a essa mesma elite.

Mesmo correndo o risco de uma interpretação exagerada, só a possibilidade de a elite intelectual brasileira considerar ser escarnecida pelo populacho como encontramos na obra é, em si, um sinal de mudança característica dos anos 1980. Também não se pode menosprezar o fato de que, no período ditatorial, a situação que era "história" - ou, noutros termos, que fazia parte de nossas indigentes tradições políticas - se agravou. Afinal, é notório que as práticas de opressão desferidas pelos órgãos oficiais da ditadura não criaram mecanismos alternativos para mediar as insatisfações e reivindicações sociais que, a partir do golpe de 1964, só cresceram em função das políticas públicas instauradas pela ditadura, que aprofundaram um quadro social historicamente grave.

Nos anos que se seguiram ao golpe, especialmente à sua radicalização no final dos anos 1960 com a decretação do AI-5 (1968), ocorreu que os segmentos populares, compostos por recém-chegados das zonas rurais, puderam agir na esfera pública de forma mais autônoma. Livres das formas tradicionais de ação política que sempre os excluía das hostes do poder e das decisões de Estado, mas também alheios às interpretações canônicas sobre "sua condição" e a "sua realidade", segundo os quais eram considerados "manipulados" em suas aspirações e reivindicações (WEFFORT 1978), estes segmentos da população puderam empregar registros menos maniqueístas para apreender o mundo que os cercava, ao negociarem, cotidianamente, as condições de sua sobrevivência com órgãos do poder instituído (SADER, 1988).

Ao cumprirem essa trajetória, os movimentos sociais brasileiros operaram uma carnavalização - para empregar um termo de caráter mais cultural ${ }^{17}$ - dos procedimentos políticos voltados para alcançar conquistas sociais e econômicas. Mesmo que muitas vezes influenciados por ex-membros da esquerda, a verdade é que esses movimentos ganharam legitimidade empregando, frequentemente, argumentos oficiais a seu favor, apropriando-se e subvertendo os significados dos discursos sobre "cidadania" que Ihes eram impingidos pela ditadura. ${ }^{18}$

\footnotetext{
${ }^{16}$ Sobre os autores que escreveram sobre o tema, merecem destaque Hobsbawm (2002), Anderson (2005) e Balakrishnan (2000).

17 Apropriamo-nos do termo bakhtiniano, empregando-o aqui no sentido de apreender um deslocamento de significados e valores operado na sociedade brasileira. Referimo-nos às mudanças fundamentais ocorridas na esfera cultural, engendradas pelos movimentos sociais desde os anos 1970/1980, na América Latina em geral e no Brasil em particular, cujo traço característico é a instauração de uma cultura categorizada por reivindicar o "direito a ter direitos". Ver a respeito Dagnino (1994; 2000) e Maia (2006), especialmente, em Avritzer e Costa (2006).

${ }_{18}$ Argumento defendido por Sader (1988).
} 
Nos anos 1980, talvez em decorrência do ocaso das ditaduras na América Latina, esse caráter dos movimentos sociais culminou por revelar um potencial transformador insuspeitado. Ao contradizerem análises "clássicas" sobre seu papel social e político, os movimentos sociais latino-americanos converteram-se então em fenômenos reconhecidos e para os quais convergiram os olhares de cientistas sociais de todo o mundo.

\section{Uma minissérie em diálogos: os movimentos sociais dos anos 1980 e a cultura política engendrada por eles}

No caso brasileiro, não seria errado considerar que a televisão cumpriu um papel importante no processo de desenraizar e modernizar as tradicionais práticas políticas, mesmo que a dimensão e extensão de sua participação ainda não tenham sido devidamente esclarecidas (SKDIMORE 1988; SODRÉ 1984). Isso ocorreu porque, embora apoiando o golpe e a ditadura - de forma velada ou não ${ }^{19}$ - as empresas de comunicação continuavam a depender de audiência para posicionarem-se no incipiente mercado de consumo brasileiro, inclusive o de bens simbólicos. Assim, essas empresas eram obrigadas a manter profissionais em seus quadros que, não obstante suas declaradas escolhas políticas (de esquerda), fossem capazes de assegurar a fidelidade do público aos programas que veiculavam. ${ }^{20}$

A manutenção de quadros da esquerda entre seus funcionários, alguns deles de reconhecido destaque ${ }^{21}$ foi um fenômeno que ocorreu em todos os setores da incipiente indústria televisiva que se consolidava no país, mas sobretudo nas áreas ligadas à telenovela - a maior responsável pelo lucro e pela fidelidade da audiência. ${ }^{22}$ Um aspecto contraditório, mas que nem mesmo a ditadura pode evitar e que, nos anos 1980, até pesquisadores de esquerda eram obrigados a reconhecer. ${ }^{23}$

Merece atenção neste contexto histórico o fato de que, embora a televisão tivesse sido implantada no país na década de 1950, o setor somente conhece um expressivo dinamismo a partir da segunda metade da década de 1960 em diante. A explicação para que isso ocorresse então é apresentada de forma sucinta e esclarecedora por Ortiz:

Ambos os setores [empresários e os militares à frente do governo ditatorial] vêem vantagens em integrar o território nacional, mas enquanto os militares propõem a unificação política das consciências, os empresários sublinham o lado da integração do mercado (ORTIZ 1988, p. 118).

Além dos esclarecimentos fornecidos por Ortiz, é ainda importante observar que também ocorreu um avanço vertiginoso no que concerne à

\footnotetext{
19 Entre os autores que se enfatizaram esse aspecto, mesmo que de forma distinta, podemos destacar Skdimore (1988), também Sodré (1984), Clark e Priolli (1991), além de Kushnir (2004).

${ }^{20}$ Ver Dias Gomes (1998) a esse respeito.

${ }^{21}$ Referimo-nos a gente como os autores de obras como Dias Gomes, Jorge Amado (que não trabalhou na empresa, mas forneceu inspiração para inúmeras obras) mais uma infinidade de atores e atrizes, bem como técnicos e diretores, etc.

22 Ver a esse respeito o trabalho de Ortiz, Borelli e Ramos (1991), além de Mattelart (1991) Walter Clark e Priolli (1991).

${ }^{23}$ Sobre a questão, conferir, especialmente, Sodré (2001), Mattelart (1998) e Skidmore (1988).
} 
penetração alcançada pela televisão na sociedade brasileira, além da retomada do crescimento econômico na segunda metade da década. No período que se estende de meados da década de 1960 a meados da de 1970 também se deu a consolidação da televisão como principal veículo de comunicação do país. Um processo que decorreu, sobretudo, da ampliação do crédito ao consumidor que assegurava acesso a televisores a uma parcela maior da população, bem como de avanços técnicos e tecnológicos da indústria e de outras ações governamentais que almejavam apoiá-las. Um verdadeiro fenômeno midiático, cujo mais importante, inovador e lucrativo gênero foi a telenovela.

Vale lembrar que as características das transformações mencionadas anteriormente devem ser consideradas no bojo de outras mais amplas ocorridas no Brasil no período, como o incremento da industrialização e da urbanização. Merece atenção especial o fato de que, em meados da década seguinte, o panorama político ganhava nova configuração, com a vitória da oposição nas eleições majoritárias de 1974. Segundo analistas de época e os próprios militares, tratava-se de um fenômeno que contou com contribuição decisiva da propaganda veiculada pela televisão no horário eleitoral. ${ }^{24}$

Ao retomarmos o fio de nossa argumentação, percebemos que no novo contexto histórico e cultural que então se configurou no Brasil, as memórias que se têm como acervo para travar um efetivo "diálogo" com a minissérie não se restringiriam mais, somente, às de militantes e militares. As memórias eram, sobretudo, aquelas que vinham se consolidando a partir de novas práticas políticas, nascidas dos movimentos sociais que ganhavam autonomia, relevância e expressão na sociedade. Surgia então uma "cultura histórica" que resultava de "diálogos" entre os discursos forjados pelas elites brasileiras para representar a "História Nacional", mas também de "memórias coletivamente compartilhadas" pelos brasileiros comuns, engendradas nas suas lutas cotidianas ao longo do tempo, especialmente nas décadas precedentes, nas quais os movimentos sociais haviam se consolidado como uma força política nova e sem precedentes.

O fundamental, nesse caso, é observar que, segundo a interpretação que construímos, estas últimas "memórias" foram apreendidas, organizadas, descritas e comunicadas por meio de uma minissérie de televisão. Noutros termos, as lembranças engendradas nas lutas políticas cotidianas de membros da sociedade civil ainda não haviam sido "articuladas" em discursos mais abrangentes, convertendo-se em memórias coletivas, embora fossem partilhadas como experiência por amplos segmentos da população que, progressivamente, ganhavam a urbe, conquistavam espaço na esfera pública e reivindicavam espaço político.

Assim, uma obra que pode ser considerada como um dos gêneros mais populares da televisão brasileira, a teleficção, articulou elementos históricos em uma narrativa que, por suas características, contemplava os mais diversos discursos sobre o passado. No entanto, mais significativo é reconhecer o caráter

\footnotetext{
${ }^{24}$ Ver a esse respeito Sodré (2001), Mattelart (1998) e Skidmore (1988). Sobre a opinião dos militares, a chamada "Lei Falcão" que limitava a propaganda na televisão nas eleições seguintes é um índice claro que, para eles, também a propaganda televisiva havia prejudicado os candidatos governistas.
} 
inusitado da obra que foi capaz de incluir algumas experiências então recentes que ainda não haviam recebido articulação discursiva mais ampla e por isso corriam o risco de serem silenciadas, como ocorre frequentemente na história.

Nessa mesma perspectiva, é fundamental reconhecer que a teledramaturgia brasileira, por uma série de fatores que indicamos sucintamente acima, foi capaz de realizar uma obra de teleficção que "dialogava" com as memórias oficiais - que ganharam voz entre militantes e militares em décadas anteriores à sua exibição - mas também e, sobretudo nesse caso, com as memórias dos brasileiros comuns, nascidas nas práticas mais prosaicas da sociedade, embora (ainda) não convertidas em discursos mais abrangentes: as "memórias coletivamente compartilhadas". Tomados sob o quadro analítico elaborado anteriormente, os acontecimentos de 1992 escapam, pois, de serem considerados somente sob o viés de um fenômeno midiático e/ou político imediato e ganham densidade histórica.

Assim, uma minissérie produzida pela empresa que se caracterizou por ganhar a liderança nacional no campo dos meios de comunicação de massa apoiada pela ditadura militar, a Rede Globo de Televisão, tendo sido considerada; inclusive, como a "porta-voz oficial do regime" (SKIDMORE 1988; CLARK; PRIOLLI 1991), por uma conjunção de fatores históricos, foi capaz de cumprir um papel social no Brasil que, muitas vezes, foi atribuído ao cinema e sua produção nos países que passaram pelos processos de industrialização e urbanização mais cedo do que o Brasil e a América Latina. Resta-nos, parafraseando Marc Ferro, estudar a telenovela e outras formas de produção teleficcional e associá-los ao mundo que o produz. Afinal,

[...] imagem ou não da realidade, documento ou ficção, intriga autêntica ou mera invenção, é História; o postulado? Que aquilo que não se realizou, as crenças, as intenções, o imaginário do homem, é tanto História quanto a História (FERRO 1979, p. 203).

\section{Referências bibliográficas}

ABDALA JUNIOR, Roberto. Brasil anos 1990: teleficção e ditadura - entre memórias e história. Revista Topoi, Rio de Janeiro, v. 13, p. 94-111, 2012.

História e cinema: um diálogo educativo. Dissertação (Mestrado em Educação) - Universidade Federal de Minas, Belo Horizonte, 2003.

A história em cena: memórias da ditadura militar e os 'rebeldes' anos 1980. Curitiba: Ed. Prisma, 2016. (No prelo)

ABREU, Martha; SOIHET, Rachel; GONTIJO, Rebeca (orgs.). Cultura política e leituras do passado: historiografia e ensino de história. Rio de Janeiro: Civilização Brasileira, 2007.

ALEGRIA, alegria: enquanto os governistas trocam favores, com humor e objetividade a rebeldia adolescente toma as ruas pedindo a saída do presidente. Veja, São Paulo, n. 1248, p. 18-23, 19 ago. 1992. Semanal. 
ALVAREZ, Sonia E.; DAGNINO, Evelina; ESCOBAR, Arturo (org.). Cultura e política nos movimentos sociais latino-americanos: novas leituras. Belo Horizonte: Ed. UFMG, 2000.

ANDERSON, Benedict. Comunidades imaginadas: reflexões sobre a origem e a expansão do nacionalismo. Lisboa: Edições 70, 2005.

Anos rebeldes. Roteiroi: Gilberto Braga. Direção: Denis Carvalho, Silvio Tendler e Ivan Zettel. Direção geral: Dennis Carvalho. Produção: Rede Globo de Televisão, 1992.

AUMONT, Jacques. A imagem. Campinas: Papirus, 2001.

BAKHTIN, Mikhail (Volochinov). Marxismo e filosofia da linguagem. São Paulo: Hucitec, 1997.

- Gêneros do discurso. In:

Estética da criação verbal. São Paulo: Martins Fontes, 1992, p. 261-306.

A cultura popular na idade média e no renascimento: o contexto de François Rabelais. 3. ed. São Paulo: HUCITEC; Brasília: EDNUB, 1996.

CARRETERO, Mario; ROSA, Alberto; GONZÁLEZ, María Fernanda. Enseñanza de la historia y memoria colectiva. Buenos Aires: Paidós, 2006.

CARVALHO, Jose Murilo de. Os bestializados: o Rio de Janeiro e a república que não foi. 2. ed. São Paulo: Companhia das Letras, 1987.

82 CLARK, Walter; PRIOLLI, Gabriel. o campeão de audiência. São Paulo: Best Seller, 1991.

DAGNINO, Evelina (org.). Os anos 90: política e sociedade. São Paulo: Brasiliense, 1994.

DARTON, Robert. Cinema: Danton e o duplo sentido. In: O Beijo de Lamourette: Mídia, cultura e revolução. São Paulo: Cia. Das Letras, 1990, p. 51-63.

DAYAN, Daniel. Os mistérios da recepção. In: NÓVOA, Jorge; FRESSATO, Soleni B., FEIGELSON, Cristian (orgs.). Cinematógrafo: um olhar sobre a história. Salvador; São Paulo: EDUFUBA; Ed. UNESP, 2009.

DREIFUSS, Réne Armand. 1964, a conquista do estado: ação política, poder e golpe de classe. Petrópolis: Vozes, 1981.

FENTRESS, James; WICKHAM, Chris. Memória social: novas perspectivas sobre o passado. Lisboa: Teorema, 1994.

FERREIRA, Jorge; DELGADO, Lucília de Almeida Neves (orgs.). O tempo da ditadura: regime militar e movimentos sociais em fins do século XX. Rio de Janeiro: Civilização Brasileira, 2003.

FERRO, Marc. O filme: uma contra-análise da sociedade? In: LE GOFF, Jacques; NORA, Pierre (orgs.). História: novos objetos. Rio de Janeiro: Francisco Alves, 1979, p. 199-213. 
Cinema e História. Rio de Janeiro: Paz e Terra, 1992.

FICO, Carlos; POLITO, Ronald. A história no Brasil: elementos para uma avaliação historiográfica. Ouro Preto: Ed. UFOP, 1992.

Reinventando o otimismo: ditadura, propaganda e imaginário social no Brasil. Rio de Janeiro: Fundação Getúlio Vargas, 1997.

GABEIRA, Fernando. O que é isso companheiro. 29. ed. Rio de Janeiro: Nova Fronteira, 1987.

GIANNINI, Silvio. Romance nos porões: com a minissérie Anos Rebeldes, pela primeira vez a TV mostra o Brasil do regime militar de 1964, VEJA, São Paulo, Abril, 15 de jul. 1992, p. 86.

GINZBURG, Carlo. Sinais. In:

Mitos, Emblemas e Sinais. São Paulo:

Cia das Letras, 1989, p. 143-179.

GOHN, Maria da Glória Marcondes. A força da periferia: a luta das mulheres por creches em São Paulo: Vozes, 1985.

. História dos movimentos e lutas sociais. São Paulo: Loyola, 2001.

. Reivindicações populares urbanas: um estudo sobre as associações de moradores de São Paulo: Cortez, 1982.

GOMES, Dias. Apenas um subversivo. Rio de Janeiro: Bertrand Brasil, 1998.

GORENDER, Jacob. Combate nas trevas - a esquerda brasileira: das ilusões perdidas à luta armada. São Paulo: Ática, 1987.

HALBWACHS, Maurice. A memória coletiva. São Paulo: Vértice/Revista dos Tribunais, 1990.

HAMBURGER, Esther. O Brasil Antenado: a sociedade da novela. Rio de Janeiro: Jorge Zahar, 2005.

ISTO É. Globo não é bobo. Estreia Anos Rebelde, a série de Gilberto Braga cujo pano de fundo é o regime militar. São Paulo. Editora: Três, n. 1189, 17 jul. 1992, p.62.

ISTO É. A força da galera: a geração Coca-Cola deixa os shoppings, vai às ruas e lidera com bom humor o movimento a favor do impeachment de Collor. São Paulo, n. 1196, p. 32-36, 2 set. 1992. Semanal.

JELIN, Elizabeth. Los trabajos de la memória. Madrid: Siglo Veitiuno De España Editores, 2002.

KORNIS, Mônica Almeida. História e cinema: um debate metodológico. Estudos históricos, Rio de Janeiro, v. 5, n. 10, p. 237-250, 1992.

Uma História do Brasil recente nas minisséries da Rede Globo. Tese (Doutorado em Artes) - Escola de Comunicação e Artes da Universidade de São Paulo, São Paulo, 2000. 
KOSELLECK, Reinhart. Futuro passado: contribuição à semântica dos tempos históricos. Rio de Janeiro: Contraponto; PUC Rio, 2006.

KRACAUER, Siegfried. De Caligari a Hitler: Uma história psicológica do cinema alemão. Rio de Janeiro: Jorge Zahar, 1988.

LAGNY, Michele. Cine e Historia: Problemas y métodos en la investigación cinematográfica. Barcelona: Bosch, 1997.

LEAL, Ondina Fachel. A leitura social da novela das oito. Rio de Janeiro. Vozes, 1986 [1983].

LIMA, Venício A. de. Globo e política: "tudo a ver". In: BRITTOS, Valério C.; BOLAÑO, César R. S. (org.). Rede Globo: 40 anos de poder e hegemonia. 2. ed. São Paulo: Paulus, 2005, p.103-129.

LOPES, Maria Immacolata Vassallo de; BORELLI, Silvia Helena Simões; RESENDE, Vera da Rocha. Vivendo com a telenovela: mediações, recepção, teleficcionalidade. São Paulo: Summus, 2002.

MAIA, Rousiley; CASTRO, Maria Céres Pimenta Spíndola (orgs.). Mídia, esfera pública e identidades coletivas. Belo Horizonte: Ed. UFMG, 2006.

MARTÍN-BARBERO, Jesús. Dos meios às mediações: comunicação, cultura e hegemonia. Rio de Janeiro: Ed. UFRJ, 2003.

MARTINS F., João Roberto. O Palácio e a Caserna: a dinâmica militar das 84 crises políticas na ditadura (1964-1969). São Carlos: Ed. Universidade Federal de São Carlos, 1996 [1995; Tese defendida em 1989].

MATTELART, Micchèle \& Armand. O carnaval das imagens: a ficção na TV. 2. ed. Trad. Suzana Calazans. São Paulo: Brasiliense, 1998 [1989].

MOTA, Carlos Guilherme. Ideologia da cultura brasileira (pontos de partida para uma revisão histórica). São Paulo: Ática, 1977 [1974].

MUNAKATA, Kazumi. História que os livros didáticos contam depois que acabou a ditadura no Brasil. In: FREITAS, Marcos Cezar de (org.). Historiografia Brasileira em perspectiva. 3. ed. São Paulo: Contexto, 2000, p. 271-296.

NAPOLITANO, Marcos. Representações políticas no movimento das Diretas-Já. Revista Brasileira de História, v. 15, n. 29, p. 207-219, 1995.

OLIVEIRA, Eliézer Rizzo de. De Geisel a Collor: as forças armadas, transição e democracia. Campinas: Papirus, 1994.

ORTIZ, Renato, BORELLI, Silvia Helena Simões, RAMOS, José Mário Ortiz. Telenovela: História e produção. 2. ed. São Paulo: Brasiliense, 1991 [1989].

A moderna civilização brasileira: cultura brasileira e indústria cultural. São Paulo: Brasiliense, 1988.

PAOLI, Maria C; SADER, Eder; TELLES Vera da S. Pensando a classe operária: os trabalhadores sujeitos ao imaginário acadêmico. Revista Brasileira de História, v. 3, n. 6, 1983. 
POLLAK, Michael. Memória, esquecimento e silêncio. Estudos Históricos. São Paulo: Vértice; Revista dos Tribunais; Associação de Pesquisa e Documentação Histórica - CPDOC/FGV, 1989.

REIS FILHO, Daniel Aarão. A revolução faltou ao encontro: os comunistas do Brasil. São Paulo: Brasiliense, 1990 [1989].

; RIDENTI, Marcelo; MOTTA, Rodrigo P. S. (org.). O golpe e a ditadura militar: 40 anos depois (1964-2004). Bauru: Edusc, 2004.

RIBEIRO, Ana Paula Goulart; SACRAMENTO, Igor (org.). Bakhtin: linguagem, cultura e mídia. São Carlos: Pedro e João, 2010.

RICOEUR, Paul. La memoria, la historia e el olvido. Buenos Aires: Fondo de Cultura Económica, 2004.

RIDENTI, Marcelo. O fantasma da revolução brasileira. São Paulo: Ed. Universidade Estadual Paulista, 1993.

RÜSEN, Jörn. Cultura faz sentido: orientações entre o ontem e o amanhã. Tradução de Nélio Schneider. Petrópolis: Vozes, 2014.

- Que es la cultura histórica? Reflexiones sobre una nueva manera de abordar la historia. Tradução: F. Sánchez Costa e Ib Schumacher. 2009. Disponível em: http://www.culturahistorica.es/ruesen/cultura_historica. pdf. Acesso em: 3 jan. 2016. Original em: FÜSSMANN, K.; GRÜTTER, H.T.; RÜSEN, J. (eds.). Historiche Faszination, Geschichts Kultur Heute. Keulen, Weimar and Wenen: Böhlau, 1994, p. 3-26.

Reconstrução do passado. Teoria da História II: os princípios da pesquisa histórica. Trad. Asta-Rose Alcaide e rev. téc. Estevão de Rezende Martins. Brasília: Ed. Universidade de Brasília, 2007a.

História Viva. Teoria da História III: formas e funções do conhecimento histórico. Brasília: Ed. Universidade de Brasília, 2007b.

Historiografia comparativa intercultural. In: MALERBA, Jurandir. (Org.) A história escrita: teoria e historia da historiografia. São Paulo: Contexto, 2006.

Razão histórica. Teoria da História I: fundamentos da ciência histórica. Tradução de Estevão de Rezende Martins. Brasília: Ed. Universidade de Brasília, 2001.

SADER, Eder. Quando novos atores entram em cena. Rio de Janeiro: Paz e Terra, 1988.

SCHWARZ, Roberto. Cultura e política, 1964-1969. In: O pai de família

e outros estudos. Rio de Janeiro: Paz e Terra, 1978, p. 61-92 (Coleção Literatura e teoria literária, v. 27).

SKIDMORE, Thomas. Brasil: de Castelo a Tancredo, 1964 a 1985. Trad. Mario Salviano Silva. Rio de Janeiro: Paz e Terra, 1988. 
SODRÉ, Muniz. O monopólio da fala: função e linguagem da televisão no Brasil. 7. ed. Petrópolis: Vozes, 2001 [1977].

STAM, Robert. Bakhtin : da teoria literária à cultura de massa. São Paulo: Ática, 1992.

; SHOHAT, Ella. Crítica à imagem eurocêntrica. São Paulo: Cosac Naify, 2006.

SWAIN, Tânia Navarro (org.). História no plural. Brasília: Ed. da UnB, 1994.

SYRKIS, Alfredo. "Os Carbonários": memórias da guerrilha perdida. São Paulo: Global, 1998.

THOMPSON, Edward P. A economia moral da multidão In: Costumes em comum: estudos sobre a cultura popular tradicional. São Paulo: Companhia das Letras, 1998, p. 150-200.

THOMPSON, John P. A mídia e a modernidade: uma teoria social da mídia. 4. ed. Petrópolis: Vozes, 2002 [1998].

VENTURA, Zuenir. 1968, o ano que não terminou. Rio de Janeiro: Nova Fronteira, 2003 [1988].

VYGOTSKY, Lev Semyonovich. A formação social da mente. São Paulo: Martins Fontes, 1994.

. Pensamento e linguagem. São Paulo: Martins Fontes, 1993.

WEFFORT, Francisco C. O populismo na política brasileira. Rio de Janeiro: Paz e Terra, 1978.

WERTSCH, James V. Voces de la mente. Madrid: Visor Distribuciones, 1993.

- Voices of Collective Remembering. Cambridge: Cambridge University Press, 2002.

WILLIAMS, Raymond. La larga revolución. Trad. Horacio Pons. Buenos Aires: Nueva Visión, 2003.

. Literatura e marxismo. Rio de Janeiro: Zahar, 1979 [1971].

WOLTON, Dominique. Elogio do grande público: uma teoria crítica da televisão. Trad. José Rubens Siqueira. São Paulo: Ática, 1996 [1990].

XAVIER, Ismail. Do senso moral-religioso ao senso comum pós-freudiano: imagens da historia nacional na teleficção brasileira. In: LOPES, Maria Immacolata Vassallo de. Telenovela: internacionalização e interculturalidade. São Paulo: Loyola, 2004, p. 47-73.

YERUSHAUMI, Yosef Hyim. Reflexiones sobre el olvido. In: YERUSHAUMI, Yosef H. et al. Usos del olvido. Buenos Aires: Nueva Visión, 1989.

- Zajor: La historia judía y la memoria judía. Rubí: Anthropos; México: Fundación Cultural Eduardo Cohen, 2002. 